\title{
Negociações sociais para melhoria das condições de trabalho no setor de teleatendimento: 0 descompasso entre a posição das empresas e a realidade do trabalho
}

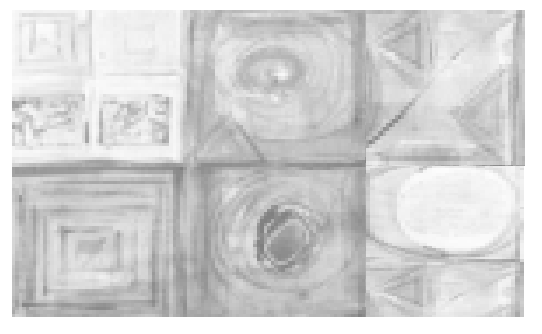

\author{
Airton Marinho Silva ${ }^{1}$ \\ Ada Ávila Assunção ${ }^{2}$
}

MARINHO-SILVA, A; ASSUNÇÂO, A. A. Social negotiations for improving work conditions in the telemarketing sector: the gap between the corporate point of view and the reality of work. Interface - Comunic., Saúde, Educ., v.9, n.18, p.553-70, set/dez 2005.

This article studies the interaction between telemarketing companies, government bodies concerned with worker health (assisted by university researchers) and a union of telephone operators. It reveals a gap between the measures companies take to face their workers' health problems and the reality of this work. Using the statements of these actors in a Public Prosecution Service Inquiry on Labor, as well as the results of bibliographic research on telemarketing operators falling ill, we studied the position adopted by companies vis-à-vis the risks associated with telemarketing work. We concluded, based on the companies' declarations, that they adopt a position of denial of the risk factors that cause telemarketing operators to fall ill, while confronting the government's labor protection requirements, which evidences the insufficiency of the workers' actions and the limitations of government power in this field.

KEY-WORDS: worker's health. telemarketing. occupational diseases. health surveillance. working conditions. occupational risk.

Estudou-se a interação entre empresas de teleatendimento ("telemarketing"), órgãos públicos interessados em saúde dos trabalhadores, assessorados por pesquisadores universitários, e entidade sindical de telefonistas, apresentando o descompasso entre as medidas tomadas pelas empresas para enfrentar os problemas de saúde dos trabalhadores e a realidade do trabalho. Partindo das manifestações desses atores em inquérito do Ministério Público do Trabalho e de estudos bibliográficos sobre o adoecimento de teleatendentes, analisam-se as posições das empresas em relação aos riscos gerados pelo trabalho em teleatendimento. Conclui-se, baseando-se nas manifestações empresariais, que existe uma posição de negação dos fatores de risco para adoecimento ocupacional dos teleatendentes e, ao mesmo tempo, de enfrentamento das exigências do setor público de proteção ao trabalho, evidenciando insuficiência das ações dos trabalhadores e limites do poder público nesse campo.

PALAVRAS-CHAVE: saúde do trabalhador. teleatendimento. telemarketing. doenças ocupacionais. vigilância em saúde. condições de trabalho. riscos ocupacionais.

\footnotetext{
* Os autores agradecem à Procuradora do Ministério Público do Trabalho, Dra Maria Helena Guthier, que possibilitou a realização deste trabalho.

${ }^{1}$ Auditor Fiscal do Trabalho do Ministério do Trabalho e Emprego, Belo Horizonte, MG. <airtonmarinho@uol.com.br>

${ }^{2}$ Professora, Departamento de Medicina Preventiva e Social, Universidade Federal de Minas Gerais, Belo Horizonte, MG.<adavila@medicina.ufmg.br>

${ }^{1}$ Rua São Romão, 555, ap. 500

Belo Horizonte, MG

30.330-120
} 


\section{Introdução}

Este artigo tem como objetivo apresentar o descompasso entre as medidas tomadas pelas empresas para enfrentar os problemas de saúde dos trabalhadores e a realidade do trabalho. Para isso, estudou-se um grupo de empresas de teleatendimento que foi motivo de denúncias ao Ministério do Trabalho e Emprego (MTE) e ao Ministério Público do Trabalho (MPT), a partir de grande número de queixas enviadas pelos trabalhadores ao Sindicato dos Trabalhadores em Empresas de Telecomunicações, Telefonia Móvel, Centros de Atendimento, Call Centers (...), Telemarketing (...) no Estado de Minas Gerais (Sinttel-MG). Denunciam-se especialmente doenças profissionais $e$ condições inadequadas de ambientes e organização do trabalho, incluindo rígido controle de tempo, baixos salários e grandes exigências de produtividade. Relatos de outros setores econômicos que utilizam grandes Centrais de Atendimento (ou "call centers") indicam situações similares, como no caso da área bancária e no atendimento a clientes comerciais. Esboçase o argumento de que as novas formas de utilização do aparato tecnológico telemático permitem uma aceleração sem precedentes no trabalho nos meios de comunicação, assim como no controle sobre os trabalhadores, o que estaria na origem das queixas registradas (Sinttel-MG, 2001). Partiu-se do princípio de que os estudos de casos permitem abordar fenômenos dentro de contexto de vida real, utilizando-se múltiplas fontes, evidenciando que, por trás dos discursos aparentes, há sentidos, padrões e relações a serem explorados.

\section{Estratégia metodológica}

Decidiu-se por um formato metodológico de análise qualitativa adequado para trazer material para a discussão dos desafios e das necessidades de regulamentação pública das condições de trabalho nesse setor no Brasil. Trata-se de análise descritiva, utilizando estudo detalhado de documentos $e$ bibliografia pesquisada sobre o tema de teleatendimento, acrescida de estudo de caso específico de interação entre Sindicato de Trabalhadores, empresas de teleatendimento e órgãos públicos (Marinho-Silva, 2004).

As ciências da saúde estão marcadas pelo pensamento determinista que supõe uma objetividade de perfeita previsão sobre as ocorrências da natureza. Daí apresentar-se uma falsa oposição entre métodos quantitativos, ditos objetivos, e métodos qualitativos, ditos "subjetivos". Essa posição carece de pertinência e reflete intolerância, "inimiga da ciência e da verdade" (Pereira, 2001).

Nas situações em que se procura o entendimento de fenômenos desconhecidos em sua totalidade e complexidade, é possível que uma análise qualitativa seja a mais indicada (Godoy, 1995). Este é o pressuposto adotado nesta pesquisa, ao estudar-se o enfrentamento e a negação das empresas quanto às condições de trabalho em teleatendimento ('telemarketing').

Pesquisas qualitativas servem-se de múltiplas fontes de dados, de observações inéditas do real, de entrevistas abertas ou relatos, em contraposição à ênfase em números, tabelas e modelos estatísticos. Perseguese o cotidiano, em contexto de descobrimento e exposição de determinado fenômeno (Godoy, 1995).

A análise de documentos, os estudos de casos, as entrevistas, a observação 


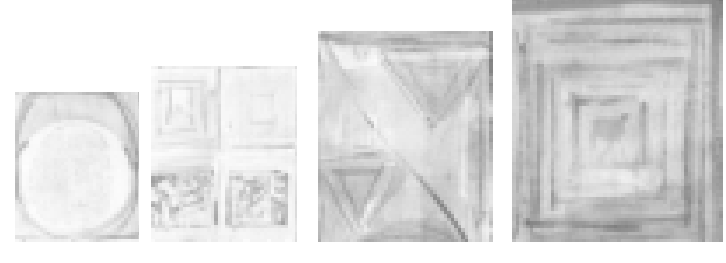

direta, são alguns dos métodos utilizados em pesquisa qualitativa, servindo de forma complementar ao entendimento do fenômeno.

A partir de uma pré-seleção, a análise de seu conteúdo consiste em explorar o material disponível procurando padrões, tendências ou relações implícitas. Interessa ao pesquisador o conteúdo latente, o sentido complexo, estrutural, que se encontra por trás do imediatamente apreendido (Godoy, 1995).

Os estudos de casos, por sua vez, permitem responder ao "como" e "por que" certos fenômenos ocorrem, forma de abordagem ideal para questões atuais, que só poderão ser analisados dentro de algum contexto de vida real. O objetivo é conhecer profundamente uma dada unidade social, utilizandose múltiplas fontes de evidências e ampla informação sobre o tema, obtidos por meio de cuidadosa revisão de literatura. Deve-se demonstrar a multiplicidade de dimensões presentes, uma vez que a realidade é sempre complexa (Godoy, 1995).

\section{Procedimentos}

\section{Análise das audiências}

Foram acompanhadas as negociações entre trabalhadores e empregadores $e$ intervenções do MPT, analisando-se as manifestações dos trabalhadores, por meio de seus representantes, as exigências legais dos órgãos públicos $e$ as formas de resposta das empresas estudadas.

Foram observadas e analisadas as interações dos atores, suas propostas, seus consensos e conflitos. Associando esses dados à discussão de elementos teóricos, levantaram-se subsídios para a discussão e reflexão sobre medidas de proteção da saúde dos teleatendentes. A premissa constante $e$ fundamental é a valorização do conhecimento científico na área de saúde e trabalho para o desenvolvimento de políticas de qualquer setor econômico.

As três audiências públicas tiveram duração média de três horas cada uma. Foram gravadas integralmente, procedendo-se, a seguir, à degravação $e$ transcrição em texto, realizando-se o estudo das manifestações dos participantes, categorizadas por temas de interesse para o estudo.

As empresas envolvidas representam de forma significativa o setor de teleatendimento ("telemarketing") em Minas Gerais, conforme quadro a seguir, sendo que, para os fins deste trabalho, consideramos empresas de pequeno porte $(P)$ aquelas com menos de cem empregados em teleatendimento e de grande porte $(G)$ aquelas acima de quinhentos empregados na atividade específica: 
Quadro I - Tipo e porte das sete empresas envolvidas no Inquérito Civil Público

\begin{tabular}{|c|l|c|}
\hline Empresa & Tipo de organização & Porte \\
\hline $\mathbf{1}$ & Concessionária de telefonia móvel & $\mathrm{G}$ \\
\hline $\mathbf{2}$ & Operadora do ramo financeiro & $\mathrm{G}$ \\
\hline $\mathbf{3}$ & Prestadora de serviços para telefonia e outros setores & $\mathrm{G}$ \\
\hline $\mathbf{4}$ & Concessionária de telefonia interurbana & $\mathrm{G}$ \\
\hline $\mathbf{5}$ & Prestadora de serviços de "telemarketing" & $\mathrm{P}$ \\
\hline $\mathbf{6}$ & Concessionária de telefonia móvel & $\mathrm{G}$ \\
\hline $\mathbf{7}$ & Prestadora de serviços para telefonia e outros setores & $\mathrm{G}$ \\
\hline
\end{tabular}

\section{Pesquisa documental}

Estudou-se um Inquérito Civil Público, procedimento investigatório levado a cabo pela Procuradoria do MPT, perante denúncias envolvendo grandes empresas de teleatendimento, no sudeste brasileiro, empresas que vêm sendo motivo de demandas junto ao MTE, ao MPT e à ANATEL, a partir do SINTTEL-MG. A documentação processual pertinente é volumosa, envolvendo dados sobre o adoecimento dos trabalhadores, relatórios de vistorias, análises técnicas, pareceres jurídicos, entre outros, configurando, em 2003, 1192 páginas. Um dos principais documentos analisados foi o relatório de pesquisa desenvolvida pela UFMG por solicitação do MPT, no qual se fez análise ergonômica detalhada, estudando a atividade dos empregados de grande empresa prestadora de serviços de teleatendimento. Essa análise foi apresentada pelos pesquisadores em uma das audiências públicas analisadas, como parte de Procedimento Investigatório do MPT.

Foram também analisados os seguintes documentos: correspondência eletrônica e postal provinda de teleatendentes e dirigidas ao SINTTEL MG, em número de 24 cartas, datadas de janeiro a junho de 2002; relatórios de quatro inspeções a empresas de "call centers", disponíveis no arquivo da DRT-MTE-MG; processo de Inquérito Civil Público em andamento na MPT, relativo a sete empresas que se dedicam a teleatendimento; transcrição de gravação de três audiências públicas, partes do processo de Inquérito referido; relatório técnico (Análise Ergonômica do Trabalho) desenvolvido pela UFMG em uma das empresas participantes; relatórios de discussões do "Seminário de Atividade de Teleatendimento/Telemarketing no Setor de Telefonia", realizado pelo MTE em São Paulo, em outubro de 2002; normas da ANATEL para a telefonia no Brasil; convenções coletivas do ano de 2002 de duas entidades sindicais de trabalhadores de empresas de telefonia $e$ teleatendimento; propostas internacionais sobre condições de trabalho em teleatendimento, provindas de órgãos governamentais e organizações de trabalhadores do Reino Unido e da Austrália.

\section{Resultados}

Para fins de clareza, subdivide-se, a seguir, a apresentação dos resultados segundo a manifestação dos atores envolvidos, expressando-se a forma de ação do MPT no caso, a posição sindical dos trabalhadores, os principais pontos do estudo desenvolvido pela UFMG e a argumentação das empresas submetidas ao inquérito. 
'A expressão "logado" é utilizada para informar que o teleatendente está conectado ao sistema telemático naquele período.

\section{A atuação do MPT}

Nas audiências públicas estudadas, as exposições da Procuradoria do MPT mostraram que a instituição buscou conhecer a organização do trabalho e as formas de adoecimento nas empresas de teleatendimento, a partir das denúncias recebidas. O MPT utiliza em seus procedimentos o estudo de documentos, procedimentos inquisitivos, inspeções locais e audiências públicas. Agrupa empresas do mesmo ramo em um único procedimento de Inquérito Civil Público quando for desejável, como é o caso atual, objetivando obter parâmetros mínimos acerca das condições de trabalho de um determinado setor, facilitando a investigação. Segundo a Procuradoria, além do agrupamento de empresas do mesmo setor, escolheu-se, no caso atual, uma empresa específica para estudo detalhado, com base em acessibilidade geográfica, número de empregados e atividade representativa dentro do conjunto das empresas.

\section{Análise ergonômica do trabalho - pontos principais da análise da UFMG}

Por solicitação do MPT, pesquisadores da UFMG realizaram estudo de condições de trabalho em uma das empresas envolvidas, cujo relatório está anexado ao processo do Inquérito.

O modelo da pesquisa ancorou-se nos ensinamentos da ergonomia, ciência que permite investigar associações entre queixas e modos de organização do trabalho. O estudo estabeleceu "recomendações no sentido de amenizar a nocividade de trabalho", segundo os pesquisadores, havendo "contradições fortes entre métodos de gestão e metas comerciais...". Estudou-se detalhadamente o trabalho em teleatendimento, utilizando equipe de pesquisadores, durante vários meses. Constam dos resultados detalhes quantitativos e qualitativos da atividade dos teleatendentes, organização do trabalho, das exigências de produtividade e metas a alcançar, dos resultados reais do trabalho e das formas de avaliação e controle utilizadas pela empresa.

O estudo, desenvolvido por Assunção E Vilela (2003), mostra com clareza e detalhes a intensa carga cognitiva de trabalho, as pressões de tempo e a rigidez do controle sobre os teleatendentes. A avaliação do desempenho, segundo as autores, é feita tomando-se por base a qualidade do atendimento, tempo médio de atendimento (TMA), assiduidade e pontualidade, tempo 'logado' 3 e relacionamento interpessoal. Constata-se que são freqüentes os estímulos à produtividade por meio de "campanhas motivacionais" e oferecimento de folgas vinculadas à ultrapassagem de determinadas metas quantitativas de vendas ou ligações.

Tendo em vista que essa forma de trabalho pode ser a raiz do adoecimento e sintomas dos trabalhadores, o mesmo estudo sugere modificações nas formas de trabalho procurando garantir a qualidade do serviço prestado sem prejudicar ou provocar sintomas nos trabalhadores. As principais propostas referem-se à discussão e definição de metas de produtividade incluindo a representação dos trabalhadores, abolição de sinais sonoros ou luminosos sobre a duração do atendimento, avaliações de desempenho em que os critérios de qualidade sejam ligados à capacidade de 
resolução de problemas e não à capacidade de seguir procedimentos prescritos, qualificação e formação necessárias para atendimento aos usuários, garantia de pausas regulares de dez minutos a cada hora trabalhada, não imposição de "tempo médio de atendimento" (TMA), avaliação e controle de produção não baseadas em índices de produtividade ou absenteísmo e, finalmente, que as gravações de atendimentos dependam do consentimento dos trabalhadores.

\section{A posição do Sindicato dos Trabalhadores}

O Sindicato dos Trabalhadores explicou sua posição no processo, visto que as denúncias ao MPT teriam sido posteriores a tentativas malsucedidas de entendimento com as empresas. Haveria um "massacre psicológico" dos jovens trabalhadores com prováveis seqüelas futuras. Ao ver da entidade, as empresas estariam envolvidas primariamente com questões econômicas, não atentando adequadamente para o ser humano. Os trabalhadores demonstraram concordância com o estudo apresentado pela UFMG, entendendo ser a descrição "... totalmente fiel à forma como é realizado o trabalho", mesmo havendo diferenças de uma empresa para outra. Foi ressaltado o caráter universal das conclusões do estudo e que a origem dos problemas dos trabalhadores que a entidade tem suscitado estaria exatamente nos fatores apontados. As formas de trabalho e controle nas empresas de teleatendimento seriam muito similares, segundo a entidade, independentemente do objetivo desse atendimento, ou do ramo econômico da empresa.

\section{A posição das empresas}

- tentativas de esvaziamento da negociação

Perante as denúncias e o estudo científico apresentado, as empresas responderam com manobras de procrastinação do processo, incluindo requerimentos para adiamento das audiências públicas e protestos contra a divulgação dos dados levantados. A representação das empresas foi feita por advogados e prepostos, sendo que apenas uma delas enviou Médico do Trabalho para participar das discussões. Foram feitas várias restrições, como, por exemplo, alegar que o objetivo específico do atendimento telefônico geraria situações "muito distintas" de trabalho e de organização e que não seria possível agrupar e generalizar problemas e observações de uma empresa para outra. Haveria "diferenças marcantes" nos trabalhos de telemarketing segundo fossem eles "passivos" ou "ativos", e que as situações deveriam ser examinadas separadamente. Existiriam, ainda ao ver dos empregadores, diferenças também entre situações de centros de atendimento a clientes próprios e aqueles de venda de produtos de terceiros. Estes últimos teriam que "produzir muito mais", enquanto os primeiros teriam como preocupação principal "atender o cliente com qualidade". Segundo a manifestação empresarial, existiriam empresas que permitiriam a seus empregados formar comissões e "debater com o empregador a metodologia de trabalho, o tempo médio de ligação, a forma de atendimento... o uso do 'script' pré-determinado". Haveria, então, variação "muito grande" no universo do teleatendimento, com diferentes métodos 
de trabalho, treinamento e avaliação, e controle de seus empregados. Os centros submetidos à regulação governamental da ANATEL, por exemplo, teriam ainda de atender a "obrigações legais" de tempos de atendimento.

Apesar das alegações, nenhuma das empresas estudadas trouxe às audiências avaliadas o detalhamento de suas atividades ou de intervenções na área de ergonomia e organização do trabalho visando melhorias das condições de trabalho e saúde de seus empregados. Até mesmo os resultados de estudos encomendados pelas próprias empresas, constantes previamente do processo do inquérito, não foram trazidos a público.

\section{O conflito entre os atores expresso nas audiências}

- As jornadas de trabalho

Os esquemas de horários seguiam jornadas de "seis horas diárias". Os sindicalistas presentes afirmaram, no entanto, que, na realidade, o intervalo obrigatório legalmente, de quinze minutos, é "cobrado" ao final da jornada, sendo o horário efetivo assinalado de seis horas e 15 minutos, diariamente. Esse dado foi confirmado pelas representações das empresas.

- O número de atendimentos

Apenas uma das empresas trouxe dados sobre suas estatísticas de atendimento, seus operadores atendem de sessenta a oitenta ligações por dia, com tempo médio de atendimento da ordem de três minutos a três minutos e dez segundos por chamada. Os dados do levantamento da UFMG, que envolvem tempos médios de atendimento de até 28 segundos por chamada em setores específicos, não foram contestados pela empresa estudada.

- As pausas oferecidas

Os esquemas de pausas no trabalho oferecidos pelas empresas são pouco variáveis. Geralmente fazem-se dois períodos de pausa, somando em torno de 25 a trinta minutos, em jornadas de seis horas e 15 minutos de duração, incluindo o intervalo obrigatório de 15 minutos da legislação trabalhista. Os representantes das empresas afirmaram, explicitamente, que os momentos das pausas são determinados pelo tráfego telefônico.

Argüidas sobre a existência de trabalho aos domingos e de autorização para tal, apenas uma das sete empresas não trabalhava aos domingos e os advogados da maioria delas disseram não ter conhecimento da existência da obrigação de uma autorização expressa do MTE para trabalho aos domingos nessa atividade, conforme as leis trabalhistas.

- Prêmios e bonificações por produção

Uma das empresas relatou que, além do salário, paga "10\%" além do salário base por "assiduidade, pontualidade, cumprimento dos tempos médios de atendimento (TMA), quantidade e qualidade do atendimento e utilização do script". Outras relataram promover freqüentemente concursos como "o melhor operador por ilha"; " a melhor equipe (líder)" com prêmios incluindo "jantares, festas, ingressos de cinema".

- Formas de controle do trabalho e do tempo de atendimento

As empresas consideram procedimento de rotina o controle dos tempos de atendimento e apresentaram vários mecanismos para esse controle. Em algumas há painéis eletrônicos nas paredes para controle de fila de usuários 
em espera e número de atendimentos. Algumas empresas utilizam sinalização de tempo de chamada por meio de mudanças de cores e símbolos nas telas dos computadores, como no caso da empresa estudada pela UFMG.

A utilização de câmeras de filmagem nos ambientes de trabalho foi confirmada por algumas empresas, sendo dito que esse fato não "incomodaria" os trabalhadores, porque seria "informado" a eles em seu treinamento.

- Terceirização: estratégia de administração de demandas e seleção de pessoal

A representação sindical apontou a existência de formas diversas de terceirização nas empresas. Algumas empresas assumiram utilizar "trabalhadores temporários em situações de picos" enquanto outras assumiram manter "estagiários intermediados por entidade empresarial", cuja atuação na empresa serviria de "porta de entrada" para contratação posterior. Uma das empresas mantém, por exemplo, 170 estagiários em atividade de trabalho de teleatendimento, em um universo de 1200 trabalhadores.

- Em defesa do "script"

As empresas manifestaram-se sobre as formas rígidas de direção do diálogo de atendimento afirmando que o objetivo a ser contemplado efetivamente em uma ligação seria "chegar ao ponto que o cliente precisa", para que se sinta satisfeito e "não retorne a ligação". Seria justificável, então, a fraseologia prescrita e objetiva para cada assunto. Para outra empresa, os trabalhadores perceberiam o "script" como "ajuda na tarefa", dado que teria sido obtido a partir de questionários de pesquisa: o "script" padronizado facilitaria o atendimento, por fornecer "segurança" à resposta oferecida ao cliente.

- Justificativas de escutas e gravações

As gravações dos atendimentos ("monitoria") seriam feitas em respeito ao "código do consumidor", que obrigaria as empresas a manter registros de seus atendimentos. A utilização de gravações das ligações seria, do ponto de vista empresarial, no sentido de "desenvolvimento" do operador e que não seria incomum, segundo uma das empresas, o fato de os trabalhadores pedirem para ouvir suas próprias gravações. Haveria valorização da monitoria no sentido da "relação com o cliente", justificando-se a gravação e escuta das chamadas, avaliando o desempenho de cinco a dez atendentes ao mês (sic).

- Contraposição à idéia de pressão temporal

A carga de execução de vários tipos de tarefas diferentes pelo operador seria "contrabalançada", segundo uma das empresas, pelas pausas formais da jornada, por "ginásticas" e pelas pausas possíveis quando o "movimento é menor" (sic). Para outra empresa, o "vínculo com o cliente" seria mais valorizado do que o tempo de atendimento.

- Auto-elogios: ambiente de trabalho e relacionamento

Todas as empresas tentaram demonstrar ambientes positivos de trabalho. Alegou-se, por exemplo, haver "grande integração entre os componentes de equipes" com "logomarcas" e "gritos de guerra" das equipes nas atividades motivacionais. Várias empresas alegaram manter "política de reconhecimento" realizando "eventos corporativos", pesquisas de "clima" e "oportunidades internas de promoção". Outra empresa apresentou resultados de

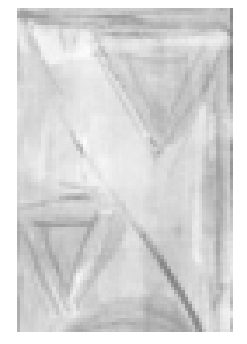


questionários sobre "ergonomia" e "clima organizacional" cujos resultados teriam mostrado "bom relacionamento com a chefia", "suficiência" dos períodos de treinamento de 176 horas (sic) e "satisfação" com a "ginástica laboral" implementada.

Assume-se a existência de competição entre as equipes, mas, ao ver de uma das empresas, isso não seria "excessivo", e não traria prejuízos aos trabalhadores.

- A desvalorização das queixas; o respaldo médico.

Para o único médico empresarial presente, os problemas em "call centers" seriam "mínimos e pouco importantes" não havendo, a seu ver, riscos de perdas auditivas e "tenossinovites ou LER/DORT"; as queixas osteomusculares seriam por problemas genéticos, "falta de relaxamento muscular" $e$ "nervosismo". Os problemas psíquicos seriam atribuíveis à "agressividade dos usuários", reconhecendo, no entanto, a existência de problemas de voz que justificariam modificações nos níveis de ruído de fundo nos ambientes de trabalho (sic).

\section{A empresa estudada pela UFMG enfrenta o MPT}

- O protesto da empresa

A empresa estudada pela UFMG alegou sentir-se em "desvantagem", e que teria "sérias restrições" aos dados apresentados, entendendo haver "prejuízos" e "intimidade devassada". O "binóculo" da pesquisa estaria "fora de foco" (sic). Muita coisa teria sido modificada em alguns meses que se passaram desde a época do estudo até a data da apresentação pública. Teria sido quebrado "segredo de justiça” na condução do processo, uma vez que dados tais como quantidade de associados e quantidade de ligações por dia seriam "dados confidenciais da empresa" que não poderiam ter sido expostos aos concorrentes. Explicou-se que o "segredo" estaria nos anexos do texto produzido pela UFMG, que trouxeram exemplos de "scripts" para atendimento, documentos gerados por "investimentos das empresas em metodologia de trabalho", considerados "segredos comerciais" (sic).

A empresa declarou ainda que "estranhava" o conteúdo do trabalho apresentado, acrescentando que se trata de ramo novo de atividade no Brasil e que não teria havido tempo suficiente para resposta às questões levantadas. A seu ver, o setor seria importante para a formação de jovens trabalhadores, além de muito relevante economicamente, e que teria havido excessos, "exagero $e$ sentimentalismo" na análise apresentada. A questão seria "muito complexa" e exigiria estudos "mais sofisticados", já que não se reconhecia no estudo e que, quando da apresentação, já se encontrava instalada em outro edifício, com condições diferentes de trabalho e "outra realidade". As conclusões teriam sido precipitadas e fruto de "visão isolada", além de que a empresa não teria sido ouvida no processo.

- A representação de empresa contra a Procuradora

A empresa na qual foi realizada a análise ergonômica apresentou, então, à Corregedoria Geral do MPT, representação contra a Procuradora responsável pelo inquérito em andamento, por entender que houve "ilícito administrativo" pela divulgação pública de dados que estariam sob sigilo judicial. 
A Procuradora apresentou sua defesa, na qual explicou a necessidade de estudo científico sobre a atividade de teleatendimento, uma vez que a documentação apresentada por todas as empresas desconsiderava a Norma Regulamentadora 17 do MTE (NR-17) nos itens que tratam da organização do trabalho. Na defesa explicou que, por exigüidade de recursos da UFMG e da Procuradoria, houve a opção de estudo em apenas uma empresa, de grande porte, na Capital, de mais fácil acesso. Houve anuência dos prepostos, tendo ficado a empresa "perfeitamente ciente de que [a pesquisa] seria utilizada para instruir todos os procedimentos investigatórios de empresas de teleatendimento". A documentação que a empresa alega ter natureza sigilosa seria essencial a qualquer análise ergonômica "e não pode ser mantida em segredo", devendo ser de conhecimento dos trabalhadores para proteção contra os riscos inerentes ao trabalho. Ainda, a Procuradora asseverou que a pesquisa não contemplou nenhum dado relativo a questões financeiras ou comerciais.

Em despacho de agosto de 2003, a Corregedora Geral do MPT acatou a defesa da Procuradora e determinou o arquivamento da representação, não dando razão às alegações da empresa.

Cabe ressaltar, uma vez que se refere a um dos atores públicos do processo em curso, que a representante da ANATEL, presente a apenas uma das audiências públicas estudadas, assumiu que não existem estudos na área de saúde do trabalhador em sua entidade.

A argumentação das empresas e as respostas do MPT estão resumidas no quadro a seguir:

Quadro sinóptico - Os argumentos apresentados nas audiências

\begin{tabular}{|c|c|}
\hline Argumentos das empresas de teleatendimento & Argumentos do MPT \\
\hline $\begin{array}{l}\text { Ocorreria grande variabilidade de formas de trabalho } \\
\text { devido aos objetivos das empresas }\end{array}$ & $\begin{array}{l}\text { Atividade de características pouco variáveis entre as empresas do } \\
\text { ramo que utilizam mecanismos similares de controle e pressão de } \\
\text { tempo. }\end{array}$ \\
\hline $\begin{array}{l}\text { Tempo exíguo para análise dos estudos apresentados } \\
\text { pelo Ministério Público. }\end{array}$ & Empresas já têm os dados nos programas oficiais devidos ao MTE. \\
\hline A empresa analisada não foi ouvida em momento algum. & $\begin{array}{l}\text { A empresa analisada está sob investigação há vários meses e teve } \\
\text { oportunidade de trazer aos autos todo o material que achasse } \\
\text { necessário. }\end{array}$ \\
\hline $\begin{array}{l}\text { Empresa analisada não se reconhece no estudo, } \\
\text { realizado sem autorização de sua diretoria. }\end{array}$ & $\begin{array}{l}\text { Estudo realizado com autorização dos responsáveis e sob } \\
\text { supervisão direta da empresa analisada. }\end{array}$ \\
\hline $\begin{array}{l}\text { Empresa teve seus segredos comerciais expostos sem } \\
\text { autorização, com prejuízos manifestos. }\end{array}$ & $\begin{array}{l}\text { O estudo científico não apresenta nenhum dado que pudesse ser } \\
\text { considerado "segredo comercial" ou merecedor de "segredo de } \\
\text { justiça". }\end{array}$ \\
\hline $\begin{array}{l}\text { Geração de empregos para jovens, em grande } \\
\text { quantidade, favorecendo sua formação. }\end{array}$ & $\begin{array}{l}\text { Geração de adoecimento entre jovens, em trabalho de mão de obra } \\
\text { intensiva, sem características de formação ou crescimento } \\
\text { profissional. }\end{array}$ \\
\hline $\begin{array}{l}\text { Teria havido excessos, exagero e sentimentalismo na } \\
\text { análise apresentada, com conclusões precipitadas }\end{array}$ & $\begin{array}{l}\text { A Procuradoria obteve da UFMG pesquisa científica, baseada em } \\
\text { metodologia ergonômica referendada internacionalmente }\end{array}$ \\
\hline $\begin{array}{l}\text { Estudo realizado em edifício diferente que o endereço } \\
\text { atual, em condições diferentes; o estudo já não poderia } \\
\text { ser plenamente considerado }\end{array}$ & $\begin{array}{l}\text { Os estudos sobre teleatendimento demonstram características } \\
\text { muito similares de trabalho e desgaste, de forma pouco dependente } \\
\text { das instalações ou de questões geográficas }\end{array}$ \\
\hline $\begin{array}{l}\text { A atividade de teleatendimento é geradora de poucos } \\
\text { riscos à saúde dos trabalhadores e já estariam } \\
\text { controlados fatores de risco à audição, sistema } \\
\text { osteomuscular e aparelho vocal, além do que os } \\
\text { problemas psíquicos seriam decorrentes de agressividade } \\
\text { de clientes (de difícil solução) e "isolamento" no trabalho } \\
\text { (em correção). }\end{array}$ & $\begin{array}{l}\text { A atividade de teleatendimento, como realizada no momento, é } \\
\text { atividade patogênica ao sistema psíquico por sobrecarga psico- } \\
\text { cognitiva desencadeada por controle estrito de tempos e modos } \\
\text { operatórios e falta de autonomia no trabalho; distúrbios auditivos e } \\
\text { de voz são freqüentes, assim como as LER/DORT. }\end{array}$ \\
\hline
\end{tabular}


Como visto, as posições dos atores envolvidos divergem substancialmente. A seguir serão discutidas as posições e manifestações dos atores envolvidos, buscando-se apoio na literatura especializada.

\section{Discussão}

A posição das empresas: o núcleo do desafio para as políticas públicas

As empresas, em contradição patente com a posição sindical e dos órgãos públicos, argumentaram que as situações apresentadas na pesquisa da UFMG não seriam comuns a todas elas, tratando-se de situações similares, mas não universais, de trabalho em teleatendimento. Essas afirmações contrastam não só com as informações e denúncias sindicais, mas também com os estudos científicos contemporâneos. Abrahão \& Gubert (1999), Abrahão \& Santos (2004), Echternacht (1998) e Sznelwar \& Massetti (2000) evidenciaram pressões gerenciais e organizacionais como característica do setor, em atenção a objetivos e metas empresariais.

A posição das empresas em negar a precariedade do trabalho e, ao contrário, salientando a adequação dos meios oferecidos para efetuá-lo, corrobora os dados de Abrahão (2003), Taylor \& Bain (1999) e Torres (2001) de que a publicidade do setor procura mostrar teleatendentes cooperativos e felizes, enquanto, na realidade, o ambiente fica permeado por queixas e sintomas constantes de estresse, envolvendo absenteísmo elevado, alta rotatividade e dificuldades cotidianas de gerenciamento e retenção de pessoas.

No mesmo sentido, entende-se o discurso de um médico que, sintomaticamente, em sua explanação, em nome de uma das empresas, de forma contrária à postura do MPT e dos trabalhadores, tentou demonstrar que haveria poucos riscos no trabalho de teleatendimento.

Contraditoriamente, no entanto, citou os principais deles, como exposição a ruído, hipersolicitação da voz, movimentos repetitivos e carga emocional da lida com o público, fatores bem descritos por autores como Abrahão $\varepsilon$ Santos (2004), Assunção \& Souza (2000), Dejours (1987), Glina \& Rocha (2003) e Sznelwar et al. (1998).

O embate entre as partes desnuda a lógica de produtividade e a negação dos efeitos sobre a saúde dos trabalhadores, coerente com o contexto da recente reestruturação produtiva, em que os trabalhadores, conforme esclarece Antunes (2003), foram fortemente atingidos pelas mudanças no trabalho, fundamentadas, principalmente, nas tecnologias de base microeletrônica e em mutações organizacionais, com maior precarização dos empregos e salários, aumentando o processo de desregulamentação do trabalho e de redução dos direitos sociais. No mesmo sentido, Ribeiro (1999) demonstra que os conflitos entre os interesses do capital, beneficiário direto da incorporação tecnológica, e as necessidades dos que trabalham subalternamente, podem emergir, catastroficamente, sob várias formas de adoecimento coletivo, como é o caso das empresas analisadas no Inquérito Civil Público objeto desta investigação.

$\mathrm{O}$ desenvolvimento das formas gerenciais atuais de controle de tempo, 
gravação de chamadas e estímulos à produção ocorreu em prazo suficiente para a elaboração e implantação de formas de alívio da carga de trabalho dos operadores, já bem estabelecidas, como explicitam Sznelwar \& Massetti (2000) e HSE (2002). A ausência de implementação das medidas conhecidas deve-se à prioridade dada pelas empresas aos métodos de gestão, reafirmando as idéias de Antunes (2002; 2003) sobre as opções do capitalismo brasileiro que permite carências das medidas de proteção à saúde dos trabalhadores, provocando condições de trabalho fortemente precarizadas, configurando, nos dizeres do autor, o "avesso do trabalho".

A ausência de profissionais de segurança e saúde do trabalho nas audiências também mostra a intenção de não discutir abertamente as questões levantadas, fugindo do ônus legal imediato, confirmando a lacuna ditada pela fragilidade da regulamentação do setor quanto à proteção à saúde dos trabalhadores, já assinalada por Dias \& Melo (2003), Lacaz (1997) e Minayo-Gomes \& Thedim-Costa (1997).

Assim, nas manifestações e ações das empresas pôde-se captar vários aspectos que permitem entender porque existem resistências em regulamentar as condições de trabalho do setor. Como já visto, as formas de controle do trabalho em "telemarketing" incluem estatísticas minuciosas de tempos e produtividade, escutas e gravações não avisadas, entre outras (Vilela E Assunção, 2004). A procura contínua do "ótimo de velocidade", nos termos de Foucault (1997), e identificadas no setor de teleatendimento leva a uma constante aceleração do trabalho, sem ociosidade ou "inutilidade". Esses controles são assumidos e apresentados com naturalidade pelas empresas, desvalorizando-se suas repercussões.

O estímulo à competição $e$ a utilização de eventos "corporativos", com metas de aumento de produtividade explícitas, foi reconhecido pelos empregadores, que tentam envolver os trabalhadores em seus objetivos, contando com seu "espírito de corpo" para objetivos comerciais. Antunes (2001) chama essas manobras de "despotismo", que é mesclado com manipulação do trabalho e um envolvimento incitado dos trabalhadores, mediante processo ainda mais profundo de interiorização do trabalho alienado. Essa situação foi descrita por Le Guillant et al. (1984) como fator de tensão e angústia, pois gera reduções dos tempos de atendimento $e$ aumento de produção pela grande competição entre as equipes de trabalho, sem que se valorize o desgaste decorrente.

A posição empresarial considera como sendo naturais e necessárias as características da organização do trabalho em "call centers" que estão presentes nos dados do estudo da UFMG e na literatura especializada. Essas características, porém, não são "naturais" nem, muito menos, inevitáveis, nos dizeres de Assunção (2003), uma vez que são comprovadamente geradoras de sobrecarga de trabalho. São exemplos dessas características empresariais a preocupação maior com a satisfação do cliente, independentemente das condições fornecidas para essa relação, a seleção de pessoal no interesse mercadológico e os constantes investimentos em produtividade, aceleração de processos e "eficiência".

Afirmou-se que "o setor é importante para a formação dos jovens trabalhadores". Todavia, os exíguos prazos de treinamento e qualificação e 
as exigências de tempo e produtividade utilizadas em "call centers", mostradas, claramente, na avaliação ergonômica e na literatura disponível, não demonstram nenhuma atividade concreta de formação ou desenvolvimento pessoal na empresa analisada, que não seja voltada para maior eficiência e produtividade na tarefa, longe do que se poderia denominar de forma adequada de formação de jovens trabalhadores.

Os métodos de formação identificados reproduzem os atuais processos de qualificação, voltados para um individualismo exacerbado e para a capacidade de enfrentar desafios e incertezas, não mais se baseando no conhecimento do ofício e na socialização do trabalho, como diria Druck (2001), ao enfatizar o reinado da descartabilidade, no mercado que exige, antes de tudo, flexibilidade, agilidade e racionalidade.

Percebe-se, também, uma tendência à subestimação dos fatores de risco, já demonstrados na literatura científica, considerando-se quase inevitável a presença de "stress" no teleatendimento. Os sinais de irritação com clientes também irritados são interpretados pelas empresas como "autocobrança" quanto às metas de produção (sic). Em nenhum momento, foi explicitado como essas metas são criadas e quais as conseqüências para o operador caso não as cumpra corretamente. Glina \& Rocha (2003) mostraram associação entre os conflitos qualidade/quantidade, a fila de clientes em espera, a falta de controle sobre o trabalho, o monitoramento eletrônico do desempenho, entre outros fatores, $e$ a tensão psicológica, a ansiedade, a depressão $e$ a fadiga em operadores de empresa de telefonia. As autoras confirmaram, ao contrário do defendido pelo setor empresarial, a existência de elevada sobrecarga emocional, cognitiva e física no trabalho dos operadores de "telemarketing".

As empresas admitem $e$ investem no controle estrito das ligações, no sentido de um atendimento que seria mais rápido e eficiente. Tenta-se assim justificar a existência do "script", ou fraseologia pré-formatada, a escuta e gravação de diálogos e a utilização de câmeras nos ambientes de trabalho, entre outras formas de controle. Explica-se esse controle como "defesa do consumidor" e como método de aprimoramento dessa fraseologia e dos comportamentos $e$ atitudes dos teleatendentes. Não se valoriza, no entanto, o alto custo do "stress" originado da avaliação contínua e dissimulada, do constrangimento da gravação e do controle dos diálogos sobre a saúde dos trabalhadores, como explicitam as queixas registradas junto ao sindicato $e$ aos órgãos públicos e os resultados descritos por Glina \& Rocha (2003) e Wisner (1994).

A tentativa de definir formatos fixos para o diálogo, por meio de "scripts" pré-determinados contrapõe-se à referência empresarial de que haveria "variação do trabalho para cada produto", contradição vivenciada em tempo real pelos teleatendentes no cumprimento de sua tarefa. Insiste-se nas diferenças de uma empresa para outra, na diferença e especificidade dos "scripts", contrariamente, porém, à afirmação dos trabalhadores sobre a homogeneidade dos procedimentos utilizados (Sinttel-MG, 2001). Nesse sentido, os estudos de Mascia \& Sznelwar (2000) mostram que a atividade de atendimento é complexa, independentemente das variações do "produto". Apesar da repetitividade e da curta duração de cada chamada, 
exige-se atenção constante, entendimento com o cliente e convivência com representações diferentes para a construção do diálogo, situação agravada pela rigidez dos diálogos pré-formatados e pela perene pressão de tempo e produtividade.

Em oposição à tentativa empresarial de padronização, a atividade dos operadores concretiza-se, na prática, por meio de uma permanente construção de diálogo com os clientes, como citado por Mascia e Sznelwar (2000), cada qual, porém, com representações mentais próprias, buscando, não sem esforço, uma aproximação para estabelecer a comunicação. Não se valoriza o fato de que trabalhadores estejam envolvidos em tarefas diversas (campanhas de vendas de produtos diferentes, por exemplo), dentro de uma mesma jornada, todas com fortes exigências cognitivas. Enfim, a necessidade de contornar a representação embutida na concepção da organização, cristalizada nos "scripts" e nas prescrições, gera constrangimentos aos operadores, nos moldes descritos pelos autores acima.

A variabilidade citada, as exigências de rapidez, rigidez de comportamento e fala e relacionamento com o público, são, em conjunto, segundo Echternacht (1998), Fernandes et al. (2002) e Wisner (1994), motivos de acentuação da carga de trabalho. A noção de carga de trabalho utilizada por esses autores, concordando com Guerin et al. (2001), refere-se à resultante dos processos de regulação das variáveis presentes na atividade, desenvolvidos pelos trabalhadores. A carga aumenta na medida em que diminuem as alternativas operatórias perante as variáveis das situações de trabalho. Os teleatendentes, utilizando estratégias e competências adquiridas no próprio trabalho, procuram gerir as ambigüidades da tarefa proposta: atender rapidamente e de forma padronizada uma demanda variável, sem perda de qualidade. Esse compromisso não se faz sem custos para o estado interno e para a integridade física e mental dos atendentes, como demonstram as queixas dos trabalhadores junto a seu Sindicato.

Vê-se que os achados da análise ergonômica do trabalho apresentada $e$ dos autores estudados vêm contrapor-se, frontalmente, à lógica racional de produtividade, que não leva em conta o desgaste e as competências necessárias para o desempenho das tarefas prescritas, conforme anunciam Fernandes et al. (2002). As organizações consideram natural monitorar, gravar, controlar os atendimentos, sem justificativas de trabalho para a criação de métodos de controle sobre os tempos de atendimento. Não são apresentados critérios claros ou motivos outros que não os de razão comercial, como grande pressão da concorrência, necessidades comerciais de atendimento eficiente ou cumprimento de normas estatais de qualidade. Vêse reproduzir no setor analisado a tendência exposta por Taylor \& Bain (1999) de que os empregadores em "call centers", à procura de lucros máximos e custos mínimos, mantêm constante processo de pressão $e$ competição para extrair mais valor de seus empregados, procurando controle total sobre as formas de trabalho.

\section{Conclusão}

Os resultados desta pesquisa, à luz de estudos teóricos e da constatação de interações práticas (Marinho-Silva, 2004), permitem afirmar a existência de 
contradições importantes na posição dos atores envolvidos no teleatendimento em nosso país, especialmente quanto ao controle temporal das atividades e seus efeitos sobre a saúde. A posição expressa pelos empresários estudados é de negação e de enfrentamento, o que salienta a insuficiência das ações e os limites do poder público perante o problema de saúde pública exposto.

As empresas posicionam-se como benfeitoras, formadoras de jovens, soluções contra o desemprego, mantendo ambientes de trabalho alardeados como saudáveis e motivadores. Os trabalhadores, todavia, apresentam queixas múltiplas, denunciadas pelas organizações sindicais que, por sua vez, estão limitadas pelos embaraços do desemprego, das privatizações e do desmonte recente dos direitos sociais dos trabalhadores. Viu-se, nesta pesquisa, que o fator "tempo" apresenta-se de forma proeminente em toda a discussão do trabalho atual: as empresas avaliam seus trabalhadores pelo cumprimento estrito das metas temporais de produção; as análises ergonômicas mostram as dificuldades dos trabalhadores em atender a essas exigências; as leis tentam delimitar a utilização pelas empresas do tempo dos seus empregados.

Pierre Naville (1969) afirma que a intervenção do legislador na duração do trabalho, quando ocorre, é para fazer prevalecer os interesses econômicos gerais da nação sobre o interesse imediato de uma empresa particular. $\mathrm{O}$ trabalho excessivo levaria a um "consumo" antieconômico da mão de obra, arruinando prematuramente as forças físicas do homem e encurtando sua vida de trabalho. Tendo em vista a relevância da questão, defende-se a ação dos atores sociais envolvidos, no sentido de melhorias das condições de trabalho dos teleatendentes, orientadas para a redução dos mecanismos de controle, especialmente sobre os tempos de atendimento, prática corrente da organização do trabalho, independentemente do objetivo do atendimento.

Segundo Rosso (1997), na história do trabalho, a redução das jornadas teve sempre o sentido de diminuir a exploração a que o trabalhador estava sujeito $e$ foi somente mediante lutas sociais enfrentadas pelos trabalhadores que se evoluiu nesse aspecto. Os resultados sempre provieram de debates de idéias, movimentos sociais e, freqüentemente, de conflitos envolvendo os assalariados, o patronato, o Estado e os reformadores sociais. As reivindicações sobre o tempo de trabalho são indissociáveis da natureza e da valorização do trabalho, assim como de sua organização social e técnica.

A formidável resistência à redução dos tempos de trabalho pelo patronato fica evidente. De acordo com o Dieese (1997) e Vindt \& Gedj (1997), a busca do lucro máximo e críticas à intervenção do Estado no que se considera ser assunto privado seriam algumas das razões dessa posição.

No setor de teleatendimento, a discussão do tempo de trabalho mostra-se ainda incipiente, apesar de envolver centenas de milhares de trabalhadores em nosso país. O conforto temporal depende ainda, por exemplo, da regulamentação básica de jornadas e pausas, o que, à época das telefonistas, havia sido razoavelmente estabelecido pela luta dos trabalhadores, conquistas reduzidas pela fragmentação e novas denominações da categoria dos operadores de telemarketing ou teleatendentes. Entretanto, a simples 
determinação de horários é pouco, face às atuais exigências de tempo $e$ conteúdo do trabalho telemático.

Em Marx, encontram-se elementos elucidativos para a problemática que se apresenta. Para o pensador, o adensamento das atividades permite ao patronato a utilização extra do tempo de trabalho dos trabalhadores. Prolonga-se o trabalho lucrativo abreviando-se as operações, produzindo-se em menos tempo o equivalente ao salário. O que Marx denominou de "redução da porosidade" permite grandes ganhos de produtividade e lucros, ao mesmo tempo que reduz, em parte, o impacto positivo de limitações nas jornadas quando se mantêm intervalos de descanso insuficientes e são realizados esforços patronais para eliminar os tempos de "não-trabalho" na jornada.

A regulamentação do tempo de trabalho torna-se ponto crítico quando o valor da mão-de-obra é preponderante nos custos empresariais, como é o caso. Reduções de poucos segundos em cada ligação telefônica utilizando-se do mesmo contingente de atendentes representam valores altamente significativos quando se computam milhões de chamadas semanais. Essa redução é feita, como visto, às custas de exigências temporais rígidas que acabam por afetar a saúde dos trabalhadores.

\section{Referências}

ABRAHÃO, J. I.; GUBERT, K. B. Os componentes cognitivos são predominantes no trabalho em uma central de teleatendimento? In: CONGRESSO BRASILEIRO DE ERGONOMIA, 9., 1999, Salvador.

Anais... Salvador: ABERGO, 1999. 1 CD-ROM.

ABRAHÃO, J. I. Reestruturação produtiva e variabilidade do trabalho: uma abordagem da ergonomia. Psicol.: Teoria Pesqui., n.16, v.1, p.49-54, 2000.

ABRAHÃO, J.; TORRES, C.; ASSUNÇÃO, A. A. Penosidade e estratégias de atenuação do risco: o caso das telefonistas de uma instituição pública. Estudos (Goiânia), v.30, p.85-110, jan. 2003.

ABRAHÃO, J.; SANTOS, V. O controle no trabalho e os seus efeitos no bem estar e na produtividade. In: TAMAYO, A. (Org.) Cultura e saúde nas organizações. Porto Alegre: Artmed, 2004. p.208-26.

ANTUNES, R. Trabalho e precarização numa ordem neoliberal. 2001. Disponível em: <http:// www.clacso.edu.ar/ libros/educacion/antunes.pdf>. Acesso em: 01 jul. 2003.

ANTUNES, R. Os caminhos da 'liofilização organizacional': as formas diferenciadas da reestruturação produtiva no Brasil. Idéias, v.9, n.2/v.10, n.1, p.13-24, 2002-2003.

ASSUNÇÃO, A. A. Saúde e condições de trabalho nas escolas públicas. In: OLIVEIRA, D. A. (Org.)

Reformas educacionais na América Latina e os trabalhadores docentes. Belo Horizonte: Autêntica, 2003. p.87-102.

ASSUNÇÃO, A. A.; SOUZA, R. Telemática. Cadernos de Saúde do Trabalhador. São Paulo: INST-CUT, 2000.

ASSUNÇÃO, A. A.; VILELA, L.V.O. As condições de adoecimento em uma empresa de teleatendimento (Relatório de pesquisa). Belo Horizonte: Editora Faculdade de Medicina UFMG, 2003.

DEJOURS, C. A loucura do trabalho: estudo de psicopatologia do trabalho. São Paulo: CortezOboré, 1987.

DIAS, E.; MELO, E. Políticas Públicas em Saúde e Segurança no Trabalho. In: MENDES, R. (Org.) 
Patologia do trabalho. 2.ed. rev. ampl. São Paulo: Atheneu, 2003. v.2, p.1683-720.

DIEESE. O movimento sindical luta pela redução da jornada. Bol. DIEESE, 1997. Disponível em: < http:// www.sindipetro.org.br/extra/cjuago97.htm >. Acesso em: 04 jul. 2003.

DRUCK, G. Qualificação, empregabilidade e competência: mitos versus realidade. In: GOMES, A. (Org). 0 trabalho no século XXI: considerações para o futuro do trabalho. São Paulo: A. Garibaldi, 2001. p.8190.

ECHTERNACHT, E. A produção social das lesões por esforços repetitivos no atual contexto da reestruturação produtiva brasileira. 1998. Tese (Doutorado) - Universidade Federal do Rio de Janeiro, Rio de Janeiro.

FERNANDES, S. R. P.; DI PACE, D. M. T.; PASSOS, M. F. D. Organização e condições de trabalho em telemarketing: repercussões na saúde psíquica dos trabalhadores. In: JACQUES, M.; CODO, W. (Org.) Saúde mental e trabalho: leituras. Petrópolis: Vozes, 2002. p.247-70.

FOUCAULT, M. Vigiar e punir. Petrópolis: Vozes, 1987.

GLINA, D. M. R.; ROCHA, L. E. Fatores de estresse no trabalho de operadores de centrais de atendimento telefônico de um Banco em São Paulo. Rev. Bras. Med. Trab., v.1, n.1, p.34-42, 2003.

GODOY, A. S. Pesquisa qualitativa: tipos fundamentais. Rev. Adm. Empres, v. 35, n.3, p. 20-9, 1995.

GUERIN, F.; LAVILLE, A.; DANIELLOU, F.; DURAFFOURG, J.; KERGUELEN, A. Compreender o trabalho para transformá-lo: a prática da ergonomia. São Paulo: Edgard Blücher, 2001.

HSE - HEALTH \& SAFETY EXECUTIVE (HELA). Advice Regarding Call Centre Working Practices. Disponível em: <http//:www.hse.gov.uk>. Acesso em: 01 ago. 2005.

LACAZ, F. R. C. Workers' health: an overview and challenges. Cad. Saúde Pública, v.13, p.7-19, 1997.

LE GUILLANT, L. et al. A neurose das telefonistas. Rev. Bras. Saúde Ocup., n.47, v.12, p. 7-11, 1984.

MARINHO-SILVA, A. A regulamentação das condições de trabalho no setor de teleatendimento no Brasil: necessidades e desafios. 2004. Dissertação (Mestrado) - Faculdade de Medicina, Universidade Federal de Minas Gerais, Belo Horizonte.

MASCIA, F. L.; SZNELWAR, L. I. Diálogo e constrangimentos do script na atividade de atendimento a clientes. In: SZNELWAR, L.; ZIDAN, N. (Org.) O trabalho humano com sistemas informatizados no setor de serviços. São Paulo: Plêiade, 2000. p.97-104.

MINAYO-GOMEZ, C.; THEDIM-COSTA, F. History and dilemmas in the development of the worker's health field. Cad. Saúde Pública, v.13, p.21-32, 1997.

NAVILLE, P. Prefácio. In: GROSSIN, W. Le travail et le temps. Paris: Anthropos, 1969. p.7-11.

PEREIRA, J.R. Definição de medidas: concepção de variáveis. In: PEREIRA, J. R. Análise de dados qualitativos: estratégias metodológicas para as Ciências da Saúde, Humanas e Sociais. São Paulo: EDUSP, FAPESP, 2001. p.43-54.

RIBEIRO, H. P. A violência oculta do trabalho. Rio de Janeiro: Fiocruz, 1999.

ROSSO, S. A redução da jornada e o emprego. 1997. Disponível em: <http://www.dieese.org.br/esp/ jtrab.html>. Acesso em: 01 jul. 2003.

SINTTEL-MG. Cartas enviadas por trabalhadores por via eletrônica e postal. Belo Horizonte, 2001.

SZNELWAR, L. I.; MASSETTI, M. Sofrimento no trabalho: uma leitura a partir de grupos de expressão. In: SZNELWAR, L. I.; ZIDAN, L.N. (Org). O trabalho humano com sistemas informatizados no setor de serviços. São Paulo: Plêiade, 2000. p.105-18.

SZNELWAR, L.; MASCIA, FI. L.; ZILBOVICIUS, M.; ARBIX, G. Ergonomics and work organization: the 
relationship between tayloristic design and workers health in banks and credit cards companies. São Paulo, 1998. (mimeogr.)

TAYLOR, P.; BAIN, P. An assembly line in the head: work and employee relations in the call centre. 1999. Disponível em: < http://www.klsi.org/pds/data/forumtele/ call\%20center\%20labour\%20relations.pdf >. Acesso em: 01 set. 2003.

TORRES, C. C.; ABRAÃO, J. I. A análise da atividade de operadores de uma central de atendimento: enfoque sobre a saúde. In: CONGRESSO BRASILEIRO DE ERGONOMIA, 9, 1999, Salvador. Anais... Salvador: ABERGO, 1999. 1 CD-ROM.

TORRES, C. A atividade nas centrais de atendimento: outra realidade, as mesmas queixas. 2001. Dissertação (Mestrado) - Instituto de Psicologia, Universidade de Brasília, Brasília.

VILELA, L.V.O.; ASSUNÇÃO, A. A. Os mecanismos de controle da atividade no setor de teleatendimento e as queixas de cansaço e esgotamento dos trabalhadores. Cad. Saúde Pública, v.20, n.4, p.1069-78, 2004.

VINDT, G.; GUEDJ, F. Le temps de travail, une histoire conflictuelle. Paris, 1997. Disponível em: <http://www.dieese.org.br/bol/int/>. Acesso em: 04 jul. 2003.

WISNER, A. Organização do trabalho, carga mental e sofrimento psíquico. In: WISNER, A. A inteligência no trabalho: textos selecionados de ergonomia. São Paulo: Fundacentro, 1994. p.11-52.

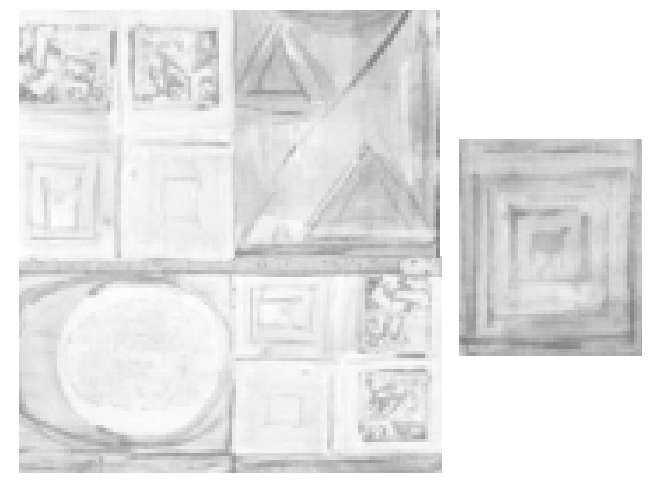

MARINHO-SILVA, A; ASSUNÇÃO, A. A. Negociaciones sociales para mejorías en las condiciones de trabajo en 'telemarketing': las discrepancias entre las actitudes de las empresas y la realidad del trabajo. Interface - Comunic., Saúde, Educ., v.9, n.18, p.553-70, set/dez 2005.

El artículo estudia las actitudes de empresas del sector de 'telemarketing' respecto a las condiciones de salud y trabajo de sus empleados frente a demandas sindicales y acciones del poder publico. El análisis del trabajo presenta evidencias de los riesgos originados en la actividad de telemarketing, en contraposición a las empresas que desvalorizan las quejas de los trabajadores. Es posible concluir, de acuerdo con las manifestaciones empresariales, que existe una posición de negación de los factores de riesgo de enfermedades ocupacionales de los trabajadores de telemarketing $y$, al mismo tiempo, de enfrentamiento a las exigencias del sector publico de protección al trabajo, lo que demuestra acciones insuficientes de parte de los trabajadores y las limitaciones del poder publico en el campo de la salud de los trabajadores.

PALABRAS CLAVE: 'telemarketing'. salud del trabajador. enfermedades ocupacionales. vigilancia en salud. condiciones de trabajo. riesgos laborales. 